\title{
A GESTÃO PARTICIPATIVA NA EDUCAÇÃO PÚBLICA BRASILEIRA: DESAFIOS NA IMPLANTAÇÃO E O PERFIL DO GESTOR.
}

\section{PARTICIPATORY MANAGEMENT IN THE BRAZILIAN PUBLIC EDUCATION: CHALLENGES IN DEPLOYMENT AND PROFILE MANAGER .}

Recebido: 07/08/2015 - Aprovado: 26/10/2015 - Publicado: 1/12/2015 Processo de Avaliação: Double Blind Review

Isac Kiyoshi Fujita ${ }^{1}$

Pós - graduado em Gestão Pública

Professor do Instituto Federal de SP

ikfujita@gmail.com

\section{RESUMO:}

Este artigo tem o objetivo de analisar a mudança na administração das escolas públicas brasileiras passando do modelo atual de gestão para um mais moderno, participativo onde o gestor deverá ser capaz de entender as necessidades da comunidade local e, ao mesmo tempo, atender as normativas do governo no Plano Nacional de Educação. Partindo da idéia de que a redemocratização criou uma abertura para a participação da sociedade civil nas decisões do governo, discutindo as suas necessidades e formando a sua agenda, os rumos que tomaram a administração pública brasileira levaram os novos gestores a tentar estabelecer uma visão sistêmica dos diversos setores e órgãos públicos. No modelo, o papel de gestor da escola acaba recaindo na figura do diretor da organização educacional e este deve ter habilidades e competências. Discutimos neste artigo quais são, de forma geral, estas habilidades e competências para termos um modelo de gestão educacional pública de qualidade e moderna.

PALAVRAS-CHAVE: 1.Gestão pública. 2.Educação. 3.Gestão participativa. 4.Qualidade. 5.Competência.

\section{ABSTRACT:}

This article aims to analyze the change in administration of Brazilian public schools from the current model to a modern way, more participatory where the manager should be able to understand the local community needs and at the same time, meet the regulations of the government in the National Education Plan. Starting from the idea that democratization has

\footnotetext{
${ }^{1}$ Autor para correspondência: Instituto Federal de São Paulo- IFSP

Rua Pedro Vicente, 625- bairro Canindé - São Paulo -SP, 01109-010.
} 
created an opening for civil society participation in government decisions, discussing their needs and forming its programming, the course that took the Brazilian government took the new managers are trying to establish a systemic view of various industries and government agencies. In the model, the role of school manager ends up falling back on the figure of the director of educational organization and this must have skills and competencies. We discussed in this article that are, in general, these skills and expertise to have a model of public education management quality and modern.

KEY WORDS: 1. Public management. 2. Participation in management. 3. Quality. 4.Competence

\section{INTRODUÇÃO}

Tem-se ampliado as discussões sobre a participação da sociedade nas decisões governamentais, porém, a cultura política ainda marcada pelo clientelismo, nepotismo aliado ao lento processo burocrático tem dificultado o processo de democratização da gestão pública no Brasil.

O processo de redemocratização - iniciado em fins de 1980 - começa a valorizar a visão sistêmica, a gestão participativa nas organizações públicas e a participação da sociedade civil nas decisões do Estado (MATIAS-PEREIRA, 2009). O próprio conceito de gestão tem no seu cerne a gestão participativa compartilhado nas organizações públicas.

Entendemos as organizações administrativas, que é o caso dos órgãos públicos, como formadas por pessoas e por isso além de fazer parte delas devem participar nela e com ela. O planejamento da participação é o que comumente chamamos de gestão. LUCK (2000) afirma que "o entendimento do conceito de gestão, por assentar-se sobre a maximização dos processos sociais como força e ímpeto para a promoção de mudanças, já pressupõe, em si, a idéia de participação ... na tomada de decisão sobre o seu encaminhamento e na ação sobre elas, em conjunto, a partir de objetivos organizacionais e abraçados por todos”.

A gestão participativa, então, pressupõe o envolvimento de todos aqueles que, de uma forma ou outra, fazem parte do processo de tomada de decisão. As habilidades que se esperam destas pessoas são o comprometimento, a busca da capacitação e a motivação de todos os membros juntamente com a responsabilidade, autonomia e voluntariedade. As escolas públicas tem sua ligação direta com a redemocratização haja vista a ampla defesa do direito à educação básica no país até sendo como um direito social. Assim a organização escolar pública não pode fugir da responsabilidade de melhorar a qualidade de sua gestão.

Sabe-se que este processo é irreversível uma vez que ele é imprescindível para o desenvolvimento econômico e social de um mundo globalizado e capitalista. Na gestão da educação não é diferente e deve quebrar um paradigma que é o modelo de gestão que ainda é vigente na maioria das escolas. Um modelo diretivo autoritário onde, segundo MACHADO (2011), a escola tinha como função apenas a implementação das políticas e decisões tomadas nas esferas superiores. 
Evidentemente, práticas correspondem a valores de suporte. A importação para ambientes de administração pública de práticas da administração privada viabiliza a circulação no espaço público dos critérios, valores e interesses a que essas práticas se reportam. Com isso diluem-se as fronteiras entre o sentido do público e o sentido do privado, em favor deste e em detrimento daquele (SILVA JÚNIOR, 2002, p. 202).

Muitas vezes o que serve para o setor privado não se aplica ao setor público, porém, pode-se aprender muito das práticas do setor privado. Estas aplicações devem-se aos objetivos antagônicos entre cada setor. Por um lado, muitas vezes, o setor privado visa o lucro, enquanto que no setor público o foco é o serviço.

\section{PARADIGMA DA GESTÃO ESCOLAR PÚBLICA}

Vários autores definem administração como um processo de coordenação de pessoas e alocação de recursos organizacionais visando alcançar os objetivos estabelecidos (SOBRAL e PECI, 2008).

O conceito de gestão vem associado ao de qualidade e principalmente na educação que deverá estar solidamente apoiado na competência de seus profissionais. Competência para oferecer experiências educativas focadas no aluno e na sociedade, em oferecer levando ao conhecimento e atitudes que permitam enfrentar os desafios da globalização, das crises econômicas, das instabilidades políticas e da formação de valores que forneçam ferramentas para a busca da qualidade nas escolas e na sociedade.

Anteriormente falamos de qualidade nas escolas e isso significa um sistema não muito simples, pois, envolvem alunos, que é o foco, professores, diretores, comunidade local. No Brasil sabe-se que as realidades locais são múltiplas e isso torna esta busca pela qualidade mais árdua. A este respeito, CARDOZO (2010) afirma que "para a construção de uma gestão realmente participativa, é necessário que sejam asseguradas as mesmas oportunidades de aprendizagem, respeito às diferenças e adaptação das escolas à realidade local”.

Nos meios públicos e governamentais, quando o assunto é a escola, uma das questões mais destacadas diz respeito à relevância de sua administração, seja para melhorar seu desempenho, seja para coibir desperdícios e utilizar mais racionalmente os recursos disponíveis (...). Embora sejam várias as motivações para essa valorização da administração escolar (...) a justificativa comum é a de que o ensino é importante e é por isso que se deve realizá-lo de uma forma mais racional e eficiente; portanto, é fundamental o modo como a escola é administrada (PARO, 2010, p.765). 
Quando falamos de administração escolar pensamos em um sistema onde se controlam notas e freqüência de alunos, próprios de um modelo de administração pública, porém este termo tem sido questionado por ser autoritário, diretivo, burocrático e mecanicista e os modelos de gestão participativa tem uma nova acepção, mais significativa e de caráter transformador.

Segundo SROUR (2003), a efetividade de uma organização está relacionada à capacidade de transformação de uma realidade social, além do que foi proposta, de forma objetiva. Considerando como um índice, esta é importante para a administração das organizações educacionais porque mostra o impacto que as suas ações tem no ambiente local.

DUSI (2012) explica o funcionamento de uma organização comparando com a organização de uma orquestra sinfônica, onde cada um dos 250 membros é especialista em alto nível, porém, sozinho nenhum deles alcança o resultado da orquestra toda. Tal resultado depende da partitura e do maestro que a conduz e dá o tom para a música.

Neste ponto podemos notar que surgem dois elementos importantes na administração: o processo administrativo (partitura) e o administrador (maestro), neles que encontramos os paradigmas que devem ser observados.

Dentro do processo administrativo são funções intrínsecas deste a definição da estrutura de coordenação do sistema de ensino, a contratação de pessoas e a distribuição de trabalho nas unidades escolares, secretarias e outros órgãos. Em muitas unidades públicas de ensino este processo é estático e qualquer mudança significa grandes esforços e pode causar até atritos pessoais.

A função do diretor e dos coordenadores de curso é servir de mediadores entre as demandas da comunidade escolar local e as políticas e diretrizes governamentais para a educação, porém estes cargos são tidos como símbolo de poder, acima de tudo, e não como serviço, apesar dos discursos.

\section{GESTÃO PARTICIPATIVA NA EDUCAÇÃO PÚBLICA BRASILEIRA}

Planejar, dirigir, organizar e controlar são, segundo SOBRAL e PECI (2008), "funções administrativas que envolvem atividades sistêmicas e de inter-relacionamento", e dentro de uma unidade escolar esta tarefa tem que ser executada de forma abrangente, pois abarca não só a comunidade local, mas os interesses das políticas públicas. Podemos dizer que há interesses internos (comunidade local) e externos (política educacional do governo).

O Planejamento define o que a organização quer alcançar no futuro, como e em quanto tempo. A partir dela o administrador pode dimensionar os recursos e tarefas necessárias. As escolas públicas têm como maior objetivo preparar o cidadão para empreender ou promover o desenvolvimento social, para tato tem que definir metas de curto, médio e longo prazo no seu planejamento. 
A Organização, no âmbito da gestão escolar, visa estabelecer os meios e os recursos necessários para possibilitar que o que foi planejado seja colocado em prática. Podemos dizer que esta é a parte relacionada com a atribuição de tarefas e requer um olhar atento do gestor para atentar ao perfil dos membros de sua equipe, suas capacidades e habilidades.

A organização constitui um "sistema aberto”, isto é, um organismo vivo em intercâmbio constante com o seu ambiente, do qual retira informações básicas para definir e rever os seus propósitos, e ao qual oferece, em troca, "bens”, "serviços”, “utilidades” julgados desejáveis e necessários [...] (ALONSO, 1976, p.78-79).

A Direção é a parte onde são utilizadas as habilidades de liderança, motivação e comunicação para que todos da equipe saibam claramente as metas a serem alcançadas. Envolver a equipe requer do gestor um investimento de tempo, de atenção e um envolvimento, distanciando-se da figura do controlador da equipe e transmissor das metas, para envolver-se e fazer parte da mesma.

O Controle representa o acompanhamento, monitoração e avaliação do desempenho da organização. O gerenciamento moderno extrapola a definição de extensos relatórios e controles sem aplicabilidade, para focar na produção e levantamento de dados e informações que possibilitem ao gestor analisar e embasar a tomada de decisões.

Não devemos ser apenas consumidores de informação, mas também criadores de informação e conhecimento. Todas as atividades devem ter como foco a aquisição do conhecimento basear-se em processos sistemáticos, embasados na geração e transferência de conhecimento.

Forma-se um ciclo repetitivo e interativo, buscando sempre a melhora do desempenho escolar como um todo, onde cada parte tem um significado e uma influência decisiva no conjunto.

Partindo desta concepção de descentralização de competências e de poder de decisão favorecendo a flexibilidade e a agilidade na tomada de decisões é possível entender como deve ser uma gestão participativa.

No entanto, quais são os requisitos para que este modelo funcione? Esta pergunta nos leva a considerar se as estruturas das escolas públicas atuais são adequadas para implantar um modelo de gestão participativa.

O que encontramos atualmente segue a linha do modelo diretivo onde, segundo PAZETO (2000), "predomina o comando a partir de decisões centralizadas na instância superior da hierarquia, cabendo às instâncias intermediárias o controle e à base o envolvimento operacional”.

O primeiro passo é perceber que neste modelo a descentralização tem papel fundamental. Há a necessidade de transferir autoridade e responsabilidade para os 
participantes de todos os níveis da organização. A descentralização favorece a rapidez nas respostas às decisões tomadas nas esferas operacionais uma vez que elas são tomadas pelas pessoas que conhecem as operações.

LUCK (200) confirma que “... sendo a escola uma organização social e o processo educacional que promove, altamente dinâmico, qualquer esforço centralizado e distante estaria fadado ao fracasso, como de fato, tem-se verificado”.

Entre outras questões, cabe, neste ponto, perguntarmos a que nível pode-se descentralizar a organização? A resposta está em outra pergunta: qual é a maturidade dos elementos da organização educacional?

Tais questões estão intimamente ligadas à construção da autonomia de cada órgão, de cada elemento da organização educacional. Podemos afirmar ainda que a autonomia é um pressuposto e estão divididas em dois tipos: a dos indivíduos e a das unidades que compões a escola, mas esta autonomia não deve ser decretada e sim construída. Logicamente a autonomia tem que ser coerente com as metas e planos estabelecidos nas diretrizes do governo. Mas como medir tal autonomia? Qual é o limite da autonomia nas decisões da escola?

Dentro deste processo deve haver um instrumento de auto-avaliação, autoconhecimento quanto à construção da autonomia dos participantes. LÜCK (2000) coloca o termo avaliação institucional como o mais adequado para medir a evolução das melhorias das práticas educativas. Estas avaliações são ferramentas, como uma espiral, em que cada volta consegue-se um incremento em termos de qualidade de ensino. Porém tudo isso isoladamente não conduz aos resultados esperados se não considerarmos o planejamento como um todo.

O alinhamento entre as diretrizes nacionais, os objetivos desenvolvidos em relação às demandas locais e os planos e ações operacionais mostra-se necessário. O planejamento estratégico é o instrumento natural para este alinhamento.

No caso do sistema educacional, o Plano de Desenvolvimento da Escola (PDE) contempla tanto o planejamento estratégico, que define diretrizes que servirão de guia para ações de melhoria da organização como um todo e para a elaboração do Projeto PoliticoPedagógico da escola, bem como o planejamento tático onde são definidos os objetivos de médio prazo nas áreas pedagógicas e administrativas. Também é onde são consideradas as estratégias operacionais: metas e planos de ação do dia-a-dia como planos de ensino e de aula, orçamentos e projetos de pesquisa.

Para integrar os níveis macro, intermediário e micro, a comunicação entre estes níveis deve ser clara e ampla e com comprometimento das partes com os objetivos do sistema e interesses da sociedade, cabe ao gestor esta comunicação.

Dentre os desafios deste gestor está à incumbência de criar os meios que garantam o envolvimento e a participação de todos. Como envolver os professores, alunos, pais, funcionários e comunidade? 
O conselho escolar é a maneira mais comum de assegurar a participação de todos os interessados na gestão escolar. Trata-se de um grupo de representantes dos pais, professores, alunos, funcionários, da comunidade e da direção, da escola que se reúne para sugerir medidas ou tomar decisões (COELHO e LINHARES, 2008, p.4).

A participação somente será eficaz se transformada em ação. Deve-se evitar, no sistema educacional, assim como em qualquer organização os discursos que não estejam alinhados a uma prática transformadora.

A criação de um grupo gestor, uma equipe com responsabilidades, que atuará conjuntamente com o administrador ou diretor, nas decisões estratégicas pode ser uma alternativa.

Algumas responsabilidades de um grupo gestor na condução do planejamento foram descritas por MACHADO (2011):

a. Decidir sobre a melhor metodologia de planejamento a ser utilizada na organização. No caso das escolas, o grupo deverá decidir qual será a melhor forma de adequar e atender as exigências quanto ao modelo de planejamento estabelecido por cada rede de ensino ou quanto às exigências estabelecidas no Plano de Desenvolvimento da Escola (PDE) e no Projeto Político Pedagógico (PPP).

b. No nível de planejamento estratégico, ele deve realizar as análises do ambiente externo e do ambiente interno da organização, identificar os seus fatores críticos de sucesso (os problemas que poderão influenciar negativamente a eficácia da organização), definir prioridades, objetivos (resultados esperados a longo prazo), diretrizes estratégicas e indicadores de desempenho e ainda determinar os meios de monitoramento e controle dos resultados. No caso das escolas, o planejamento estratégico precisa considerar como ponto de todo o processo, as diretrizes estratégicas e políticas determinadas no âmbito das redes de ensino.

c. No nível tático e operacional, o grupo gestor deve, através de cada representante de setor ou de equipe, acompanhar o desdobramento de objetivos e diretrizes estratégicas em metas e planos de ação, por setor e a elaboração de cronogramas, de orçamentos, dos meios de controle e dos indicadores de resultados. Nesse caso, deve ocorrer a delegação das decisões de nível tático e operacional para cada um dos representantes de área ou setor que integram o grupo. Munido de todas as informações sobre o planejamento estratégico (oriundas do trabalho do grupo gestor), o 
representante tem as condições necessárias para se reunir com sua equipe e conduzir o processo de planejamento tático e operacional. Ao final do processo, ele apresenta o produto final desse planejamento para avaliação e aprovação do grupo gestor. No caso das escolas, o diretor tem como responsabilidade coordenar o trabalho do grupo gestor e ser o intermediário entre o grupo e a rede de ensino.

As exigências da função mostram que são necessárias características difíceis de encontrar em um gestor. Assim o gestor deve perceber que ele não é uma pessoa pronta, que precisa de formação para a função, deve estar aberto a formar-se constantemente e assim aprender e transformar em ação o que aprendeu.

\section{PERFIL DO GESTOR ESCOLAR}

No modelo clássico e estático de gestão escolar o foco estava no número de alunos e não na qualidade do processo ensino-aprendizagem. Regras fixas e unificadas de gestão pedagógica e administrativa das escolas eram aplicadas a diferentes comunidades com características diversas e o diretor surgia como um guardião das determinações do sistema, um executor e não um gestor.

A escola, entretanto transformou-se em um modelo de administração dinâmico, onde a gestão passa a ser entendida como um processo. Este processo é exercido por uma equipe consciente da realidade escolar e comunitária.

O papel do gestor, geralmente centrado no diretor da escola, é importante pelo fato de que é dele a responsabilidade por conduzir e mediar políticas públicas da educação e os interesses e demandas da comunidade local através da gestão participativa.

LUCK (2000) destaca:

Não se pode esperar mais que os dirigentes escolares aprendam em serviço, pelo ensaio e erro, sobre como resolver conflitos e atuar convenientemente em situações de tensão, como desenvolver trabalho em equipe, como monitorar resultados, como planejar e implementar o projeto político pedagógico da escola, como promover a integração escola-comunidade.

O primeiro obstáculo é a oferta de cursos de formação de gestores escolares. LUCK (2000) observa "uma oferta insuficiente de oportunidades de formação inicial de gestores escolares”. Temos que compreender que gerenciar uma unidade educacional pública não é o mesmo que administrar uma empresa. A escola constitui-se num ambiente políticoideológico onde não é possível dissociar as tarefas pertinentes da administração e das relativas à educação. Verifica-se que o gestor da educação tem que ter habilidades e competências especifica para exercer a função. 
Alguns autores como COELHO e LINHARES(2008), LUCK (2009), MACHADO (2000) e WITTMMANN (2000) tentaram levantar algumas competências dos gestores educacionais:

- Garantir o funcionamento pleno da escola como uma organização social.

- Prever, antecipar mudanças.

- Avaliar, enfrentar desafios.

- Saber planejar e acompanhar os resultados da escola.

- Promover um diagnóstico da realidade escolar e da avaliação institucional.

- Acompanhar a evolução da sociedade e orientar as ações da escola de acordo com as demandas de aprendizagem.

- Formação de alunos e funcionários como cidadãos autônomos, críticos e participativos da comunidade escolar.

- Zelar pela realização dos objetivos educacionais.

- Direcionar a escola rumo a elevados níveis de qualidade de ensino.

Para alcançar estas competências, o gestor precisa ter liderança. No entanto, um bom líder significa um bom gestor?

Para COELHO e LINHARES (2008), a liderança se dá em dois campos: a pedagógica e de relações humanas. Salienta que administrar envolve muito mais do que liderar.

MINTZBERG (2010) afirma que hoje em dia há “excesso de liderança e falta de gestão”. Podemos concluir que há uma relação entre estes dois elementos e que a liderança separada da gestão transforma o "processo social em um processo pessoal" (MACHADO,2011).

Num ambiente tão complexo como a escola pública, faltam aos gestores parâmetros mais sólidos sobre o local. A pessoa que estamos procurando tem que ter senso de comunidade, ou seja, "buscar os interesses da organização através do alcance dos interesses da cada indivíduo que deve se responsável pela construção das partes e pelo sucesso do todo" segundo MINTZBERG (2010).

Quanto às habilidades, que é a capacidade de transformar conhecimento em ação. Robert Katz (2008) define três tipos de habilidade para os gestores:

1) Habilidade técnica que é o uso do conhecimento especializado e a facilidade de execução de técnicas relacionadas ao trabalho e aos procedimentos de realização. 
2) Habilidade humana que é a facilidade de relacionamento interpessoal além da capacidade de comunicar, motivar, coordenar, liderar, resolver conflitos.

3) Habilidade conceitual que é ter pensamento estratégico, visão sistêmica e compreensão do todo e das partes.

Estas habilidades associadas facilitam os diagnósticos das situações e a formulação de alternativas criativas para a solução das questões relacionadas à gestão escolar. Para o gestor ter visão sistêmica, segundo LAMPEL (2010), significa conhecer o passado da organização, entender o presente olhando-a por cima (o todo), por dentro (interno) e para os lados (externo) para então planejar o futuro com criatividade.

O gestor, portanto, precisa atualizar-se com estudos e leituras da área de conhecimento, ou seja, reciclar-se constantemente, pois o mundo está em constante mutação.

Estes conhecimentos adquiridos devem ser utilizados para a organização. Fazendo uma aproximação simplificada, é como o bom médico que faz uma leitura da situação do paciente e aplica o remédio certo, na dose adequada, na hora determinada, sem dar voltas, direto e às vezes doloroso, porém corta o mal pela raiz para dar nova vida ao paciente.

\section{CONSIDERAÇÕES FINAIS:}

A implantação de modelos participativos de gestão da educação está estritamente atrelada à adoção da prática da gestão estratégica nos diferentes órgãos do sistema de ensino. Os órgãos e as unidades de ensino necessitam um alinhamento e uma inter-relação para que os modelos apresentados tenham aplicabilidade e sucesso.

A gestão estratégica na educação deve contemplar as especificidades de cada unidade e conceder autonomia aos gestores, respeitando as políticas e diretrizes da educação brasileira.

De toda discussão apresentada, podemos concluir que a Gestão Participativa faz parte de um modelo de Gestão disponível para os gestores que desejam potencializar as competências presentes nas pessoas que integram as organizações. Porém não deve ser entendido como uma estratégia de diminuir as reclamações no ambiente de trabalho.

A implantação impõe desafios e o maior deles é a formação de gestores, principalmente nas organizações educacionais onde o ambiente é complexo tanto internamente como externamente.

O gestor educacional não é somente um líder, mas uma pessoa que envolve impulso e determinação em inovar, ter a convicção de melhorar continuamente a si próprio e os outros, ter um espírito empreendedor e certo inconformismo com a situação atual. Como foi dito anteriormente, a facilidade para trabalhar com pessoas é uma habilidade indispensável ao gestor, porém, influenciá-las ajudará a dar um salto de qualidade na organização 
educacional. Abraham Lincoln disse: “A maior habilidade de um líder é desenvolver habilidades extraordinárias em pessoas comuns”.

\section{REFERÊNCIAS}

ALONSO, M. O papel do diretor na administração escolar. São Paulo: Difel, 1976.

BRASIL. Constituição da República Federativa do Brasil de 1988. Presidência da República. Disponível em: http://www.planalto.gov.br/ccivil_03/constituicao/constituicao.htm. Acesso em: 06/05/2013. (capitulo III, seção I, art 206 paragrafo VI).

Ministério do Planejamento, Orçamento e Gestão. Secretaria de Gestão. Programa Nacional de Gestão Pública e Desburocratização - GESPÚBLICA. Prêmio Nacional da Gestão Pública - PQGF. Instruções para Avaliação da Gestão Pública - 2008/2009. Brasília; MP, SEGES, 2008. Versão 1/2008.

CARDOZO, R.M. D. Gestão participativa na educação profissional e tecnológica: o papel do conselho diretor. Dissertação (mestrado em Educação). Universidade de Brasília: Brasília, 2010 .

COELHO, S.B.R.;LINHARES, C. Gestão participativa no ambiente escolar. Revista eletrônica latu sensu. Ano 3, n. 1, mar. 2008.

DUSI,C.S.C.O. e PONTES, L.A.F. Avaliação de programas e políticas educacionais e gestão e liderança. Juiz de Fora: FADEPE, 2012.

GENTILI, P.A.A. O discurso da "qualidade" como nova retórica conservadora no campo educacional. In: GENTILI, P. A. A.; SILVA, T. T. (Org.). Neoliberalismo, qualidade total e educação: visões críticas. Petrópolis, RJ: Vozes, 1995.

GODOY, M. B. Os novos desafio do gestor público. Revista gestão pública. Ano XXI - T II, $\mathrm{N}^{\circ}$ 65, mai. 2013

LÜCK, H. Concepções e processos democráticos de gestão educacional.. Série Cadernos de Gestão, v.II. Petrópolis: Vozes, 2012.

Perspectivas da Gestão Escolar e Implicações quanto à Formação de seus Gestores. Brasília. V.17,n72,p11-33, fev/jun.2000.

MACHADO, M. C. da S. Gestão participativa e planejamento. CAed/UFJF, 2011.

MATIAS-PEREIRA. J. Manual de gestão pública contemporânea. São Paulo: Atlas, 2009.

MINTZBERG, H. Managing: desvendando o dia a dia da gestão. Porto Alegre: Bookman, 2010 . 
MOTTA, P.R. Transformação organizacional: a teoria e a prática de inovar. Rio de Janeiro: Qualitymark, 1998.

PARO, V.H. A educação, a política e a administração: reflexões sobre a prática do diretor da escola. Educação e Pesquisa. V.36, n.3, p. 763-778. São Paulo,2010.

PAZETO, A.E. Participação: exigências para a qualificação do gestor e processo permanente de atualização. Brasília: INEP/MEC, volume 17, n.72, 2000.

SENGE, P. M. A Quinta disciplina: arte e prática da organização que aprende. 16 ed. (Tradução: OP Traduções). São Paulo: Editora Nova Cultural, 2004.

SENGE, P. M. A Quinta disciplina: caderno de campo - estratégias e ferramentas para construir uma organização que aprende. Rio de Janeiro: Qualitymark, 1990, 1999.

SILVA JÚNIOR, C. A. O espaço da administração no tempo da gestão. In: MACHADO, L. M.; FERREIRA, N. S. C. (Org.). Política e gestão da educação: dois olhares. Rio de Janeiro: DP\&A, 2002.

SOBRAL, F.,PECI, A. Administração: teoria e prática no contexto brasileiro. São Paulo: Pearson Prentice Hall, 2008.

SROUR, R.H. Poder, cultura e ética nas organizações. Rio de Janeiro: Campus, 2003.

WITTMANN, L. C. Autonomia da escola e democratização de sua gestão: novas demandas para o gestor. Brasília:INEP/MEC. v. 17, n. 72, p. 88-96, fev./jun. 2000. 